\title{
Avaliação do Desenvolvimento de Competências Afetivas e Empáticas do Futuro Médico
}

\author{
Evaluation of the Development of Empathic \\ and Affective Skills in Future Physicians
}

\author{
Natália Souza Medeiros ${ }^{I}$ \\ Thais Rabelo dos Santos ${ }^{I}$ \\ Eliana Mendonça Vilar Trindade \\ Karlo Jozefo Quadros de Almeida ${ }^{I}$
}

\section{PALAVRAS-CHAVE: \\ - Empatia; \\ - Medicina Narrativa; \\ - Educação Médica.}

\section{KEYWORDS:}

- Empathy;

- Narration;

- Medical Education;

Recebido em: 17/06/2013

Aprovado em: 02/12/2013

\begin{abstract}
RESUMO
Dentre os desafios atuais da educação médica, encontra-se a inserção curricular de conteúdos e experiências educacionais voltados para o desenvolvimento de competências afetivas. A literatura tem indicado um declínio gradual do idealismo e humanismo do estudante ao longo do curso, indício de erosão do currículo médico. O objetivo deste estudo foi avaliar o desenvolvimento de competências afetivas e empáticas dos estudantes do curso de Medicina da Escola Superior de Ciências da Saúde (ESCS), por meio da análise de 39 narrativas produzidas por estudantes da segunda e terceira séries em 2010. A análise de conteúdo baseou-se na epistemologia qualitativa, com base na qual foram estabelecidas três categorias: ritual de iniciação do estudante: vivências e dificuldades; vivências emocionais no decorrer da formação médica; benefícios pedagógicos da medicina narrativa: os desafios do desenvolvimento da empatia. A segunda série pareceu representar para os estudantes uma fase de adaptação ao contexto hospitalar, vista a necessidade de exteriorização dos próprios conflitos e de suas barreiras emocionais. Na terceira série, observou-se melhor desenvolvimento tanto de habilidades empáticas quanto de uma visão mais integral da condição dos pacientes e seus dramas. Conclui-se que a medicina narrativa foi uma abordagem efetiva para o aprendizado da empatia e da competência afetiva nos estudantes de Medicina, além de instrumento válido em nosso meio para avaliação de competências empáticas e humanísticas. A progressiva adesão dos estudantes legitima e consolida a medicina narrativa no espaço curricular, revalorizando a formação médica em suas práticas intersubjetivas. Entretanto, este estudo aponta a necessidade de novas investigações, utilizando-se métodos mistos para melhor compreensão do impacto dessa abordagem a longo prazo.
\end{abstract}




\section{INTRODUÇÃO}

Nem sempre estudantes de Medicina demonstram interesse e habilidade empática diante dos dramas humanos associados ao adoecimento, o que pode redundar numa prática médica desumanizada. O temor da prática profissional consolidada no tecnicismo levou, em 2001, a alterações nas Diretrizes Curriculares Nacionais do curso de graduação em Medicina. A tendência biopsicossocial surgiu a partir da integração de várias áreas de conhecimento na graduação médica, como a Psiquiatria, a Psicologia, a Psicanálise e a medicina psicossomática, entre outras ${ }^{1}$.

Instaurou-se a inclusão curricular de dimensões éticas e humanísticas que propiciam ao estudante o desenvolvimento de atitudes e valores voltados à cidadania ${ }^{2}$. Os pacientes, que trazem consigo relatos pessoais, além de tratar de seus sintomas, querem compreender e dar significado às suas próprias histórias ${ }^{3}$.

Com o intuito de formar médicos mais empáticos, é necessária a valorização de novas práticas pedagógicas. Um exemplo de prática pedagógica inovadora é a medicina narrativa, assim denominada pela Dr ${ }^{\mathrm{a}}$ Rita Charon. Define-se competência narrativa como um conjunto de habilidades requeridas para reconhecer, absorver, interpretar e se mobilizar com as histórias e situações de outros ${ }^{4}$. Essa competência requer uma combinação de habilidades textuais (identificar estruturas, adotar perspectivas múltiplas, reconhecer metáforas e insinuações), criativas (imaginar diversas interpretações, ter curiosidade, idealizar finais múltiplos) e afetivas (tolerar incertezas enquanto a história se desenvolve, embarcar no clima do enredo). Juntas, essas habilidades fornecem recursos para a compreensão das informações contidas nas histórias e para o entendimento de seus significados ${ }^{5}$. A competência narrativa possibilita melhor capacidade de ouvir e acompanhar o que é relatado, reconhecendo-se as imagens e metáforas usadas pelas pessoas e adotando-se o ponto de vista do outro ${ }^{6}$.

A competência narrativa promove uma abertura na visão epistemológica do médico, na medida em que passam a ser consideradas e legitimadas múltiplas fontes de saber acerca do paciente, incluindo as informais e subjetivas, muitas vezes consideradas não científicas ${ }^{1}$.

O médico "habita o seu set" de motivos, medos, esperanças, tornando suas narrativas limitadas pelo seu ponto de vista. Um exemplo disso é a capacidade de transformar a história contada pelo paciente em dados objetivos que caracterizam o curso da disfunção biológica atual, excluindo as percepções desse paciente sobre sua doença, aflições e angústias ${ }^{4}$.

\section{Desenvolvimento de competências afetivas e empáticas e o} currículo da ESCS

O curso de Medicina da ESCS - partindo do princípio de "garantir e aperfeiçoar a formação geral do médico em termos técnicos, científicos e humanísticos", numa perspectiva interdisciplinar - tem como uma de suas metas formar profissionais com capacidade para "compreender as necessidades de saúde das pessoas não apenas do ponto de vista físico, mas no contexto psicológico, familiar, laboral e comunitário"7. Trata-se de um projeto pedagógico original e interdisciplinar que adota metodologias ativas de ensino-aprendizagem em quatro eixos, visando superar as contradições de um modelo biologicista e tecnificante ao enfocar o ser humano também em suas dimensões psicossocioculturais. Com isto, cumpre um relevante papel social comprometido com a qualidade de vida e a promoção da saúde em todas as comunidades onde atua7.

No eixo Habilidades e Atitudes Profissionais (HA), ocorre o contato entre os estudantes e os pacientes desde o início do curso, o que permite aos alunos uma visão completa dos pacientes no contexto saúde-doença. Busca-se, ainda, possibilitar ao estudante a aquisição de competências relevantes de forma estruturada e progressiva, viabilizando um espaço para a prática autorreflexiva, integração conceitual e o pensar crítico, além do desenvolvimento e aprimoramento crescente de competências do futuro médico, como o reconhecimento da importância da comunicação verbal e não verbal na relação médico-paciente ${ }^{1}$

Na segunda série do curso de Medicina da ESCS, os estudantes passam a ter mais contato com o paciente em todos os níveis de atenção à saúde. Em função disso, vivenciam diversas situações conflitantes, de cunho ético, social e humanístico. Para auxiliar os estudantes no enfrentamento dessas questões, o curso incluiu no currículo dessa série, em 2010, práticas estruturadas de medicina narrativa, que vinha sendo empregada havia algum tempo na terceira série.

A subjetividade arraigada nessas narrativas é vista por González Rey como um fenômeno complexo, que deve ser conhecido de forma mais aproximada e dinâmica por meio de métodos qualitativos. Em suas obras, esse autor traça um percurso do desenvolvimento da pesquisa qualitativa e mostra que a categoria subjetividade é passível de ser a principal proposição para investigação ${ }^{8}$. A técnica da narrativa médica também possibilita a livre expressão da subjetividade do futuro médico, o que pode contribuir para agilizar o processo de amadurecimento e de construção da identidade pessoal e profissional dele ${ }^{4}$. Além disso, as narrativas escritas possibilitam ao futuro médico não apenas um melhor conhecimento sobre o paciente e sua doença, mas um "mergulho em si mesmo", 
promovendo uma reflexão sobre suas vivências e gerando maior confiança, capacidade de reconhecer e prevenir erros, além do compromisso ético com o paciente 9 .

Existe no currículo da ESCS, portanto, um cuidado constante na abordagem de vivências e dificuldades dos estudantes no desenvolvimento de habilidades éticas, afetivas e interpessoais. O objetivo do presente estudo foi avaliar o desenvolvimento de competências afetivas e empáticas dos estudantes do curso de Medicina da Escola Superior de Ciências da Saúde (ESCS), por meio da análise de 39 narrativas produzidas por estudantes da segunda e terceira séries, em 2010.

\section{MÉTODOS}

O estudo, desenvolvido na Escola Superior de Ciências da Saúde (ESCS), é de cunho qualitativo, exploratório e transversal. Buscou-se delinear um método de estudo adequado ao tipo de realidade estudada, considerada complexa e marcada por nuances subjetivas ${ }^{7}$. Houve o cuidado de selecionar uma amostra significativa e emblemática do universo estudado de acordo com os princípios epistemológicos da informação qualitativa. Houve a preocupação de incluir na amostra sujeitos considerados informantes-chave e que preenchessem o critério da diversidade de tipos e da saturação teórica ${ }^{7}$. Realizou-se uma revisão bibliográfica nas bases de dados PubMed e Biblioteca Virtual em Saúde (BVS), contemplando artigos sobre educação médica publicados entre os anos 2000 e 2010.

\section{Seleção dos sujeitos}

O espaço amostral englobou narrativas de 39 estudantes do segundo e terceiro anos do curso de Medicina da ESCS, realizadas no ano de 2010. Utilizaram-se critérios específicos para a seleção de amostras qualitativas, emblemáticos para a realidade estudada ${ }^{8}$. No critério de saturação teórica, observa-se que os tópicos mais evidentes e significativos das narrativas começam a aparecer de forma recorrente e repetida, o que indica não haver necessidade de incluir novas narrativas e que a amostra delineada representa um universo legítimo e suficiente para a análise qualitativa da realidade.

Para garantir o respaldo das Diretrizes e Normas Regulamentadoras de Pesquisas Envolvendo Seres Humanos, do Conselho Nacional de Saúde, no convite ao estudante para participar da pesquisa, foi apresentado o TCLE, juntamente com a explicitação da finalidade do trabalho e a garantia de anonimato mediante a omissão do nome do aluno nos trechos de suas narrativas. Também foi garantido o anonimato dos pacientes com a substituição de seus nomes por fictícios. O protocolo do estudo no Comitê de Ética e Pesquisa da ESCS é de número 201.
Como critérios de inclusão, os estudantes deveriam estar regularmente matriculados na segunda e terceira séries, e manifestar o desejo de participar da pesquisa, por meio da produção de narrativas completas. Não houve estudantes convidados que se negaram a participar. O cenário de realização da pesquisa foi a rede de saúde pública do Distrito Federal. Todas as narrativas incluídas no estudo foram realizadas mediante contato com pacientes internados em hospitais secundários e terciários.

\section{Procedimentos}

Ao longo do ano letivo de 2010, os alunos da segunda e terceira séries do curso de Medicina da ESCS realizaram narrativas médicas, cumprindo objetivos do eixo de habilidades e atitudes da escola. Foram realizadas devolutivas pelo preceptor, com base em aspectos relevantes para a formação humanística do estudante e em conceitos extraídos da psicologia médica.

Os alunos receberam diferentes roteiros para elaboração destas narrativas em função do momento do curso. No segundo ano, os estudantes tiveram como foco os aspectos ligados às próprias vivências emocionais, ao ambiente psicológico da entrevista, bem como ao ambiente da enfermaria. Já no terceiro ano, busca-se, por meio das narrativas e de uma escuta qualificada, alcançar uma visão integral do paciente, que inclui relatos livres e subjetivos acerca do processo de adoecimento, aspectos semiológicos e psicológicos do paciente, a história de vida da pessoa, bem como descrever detalhes do ambiente. Nesse ano, introduz-se também a narrativa na primeira pessoa, em que o estudante deliberadamente se coloca no lugar do outro, assumindo sua voz, visão de mundo e estratégias de enfrentamento da sua condição.

\section{Análise qualitativa dos dados}

Foi realizada análise de conteúdo das narrativas médicas selecionadas, com o objetivo de interpretar os sentidos latentes apreendidos no discurso dos estudantes, o que implica uma análise não apenas descritiva, mas, sobretudo, reflexiva e dinâmica ${ }^{5}$. A obtenção dos indicadores de sentido nos permitiu construir algumas categorias de análise ou zonas de sentido, conforme os pressupostos da epistemologia qualitativa ${ }^{5}$.

Nesta perspectiva, valorizou-se tanto a relevância quanto a frequência de aparecimento dos termos. Segundo os princípios da proposta preconizada pela epistemologia narrativa, a produção científica consiste em uma forma de aproximação e diálogo com o real, visando a um conhecimento construtivo-interpretativo ${ }^{5}$.

A análise qualitativa dos dados foi crucial para a compreensão da realidade, por ser capaz de apreender de forma ver- 
tical a dimensão intensa e complexa do fenômeno estudado, o que contempla toda a dinamicidade, processualidade, subjetividade e historicidade das narrativas, visto que a informação qualitativa é considerada válida por ser capaz de produzir um modelo de inteligibilidade diferenciado e validado pelos critérios oriundos da intersubjetividade na prática hermenêutica, abrindo mão de intenções eminentemente positivistas, tais como a generalização dos achados ${ }^{5}$. Após a leitura flutuante e exaustiva do texto produzido, identificaram-se os resultados seguintes.

\section{RESULTADOS E DISCUSSÃO}

Após a análise dos textos produzidos, foi possível identificar três categorias significativas de reflexão, que representaram grandes zonas de sentido elucidativas do saber investigado. Não foram observadas diferenças significativas em termos de qualidade da produção textual entre os estudantes do segundo e do terceiro ano. Por outro lado, observou-se maior desenvolvimento de habilidades empáticas no terceiro ano, cujos estudantes já haviam tido mais oportunidades de aprendizagens significativas, de reflexões inspiradas na prática e de superação das próprias limitações. Mesmo considerando traços e estilos diferenciados e singulares de escrita e de elaboração da tarefa narrativa de cada estudante, a análise diferenciada deste material nas duas séries permitiu identificar alguns padrões recorrentes mais característicos das duas séries. No segundo ano, o teor das narrativas confirmou a necessidade, por parte dos sujeitos, de exteriorização dos próprios conflitos e de barreiras emocionais, já que esta série pareceu representar uma fase de adaptação e familiarização com o contexto hospitalar.

Ficou patente a importância pedagógica da narrativa médica durante esse verdadeiro ritual de passagem constituído pelos primeiros encontros com pacientes no segundo ano da ESCS. Muitas narrativas foram reveladoras da necessidade do estudante de preencher este espaço de expressão por meio da própria subjetividade, ou seja, pelos medos e apreensões gerados pela dificuldade diante da tarefa complexa de elaboração de anamneses e exames físicos. Os estudantes do terceiro ano demonstraram maior amadurecimento e capacidade de visão integrada do paciente, ao passo que os da segunda série demonstraram, muitas vezes, dificuldades em lidar com a densidade afetiva inerente à relação com o paciente. No segundo ano, o foco são as próprias vivências, medos e dificuldades; já no terceiro ano, ocorreu maior transcendência destas questões, e alguns alunos conseguiram visualizar o drama, os desejos e a doença do paciente de forma empática e integrada. Tal constatação nos permitiu visualizar a presença de uma integração longitudinal do currículo em termos de desenvolvimento de habilidades clínicas do estudante. Permanece o desafio de consolidarmos uma integração maior entre a prática do exame físico e o desenvolvimento da anamnese no contexto hospitalar, entendendo que as competências afetivas e empáticas permeiam todo o processo.

Ressaltamos que tais competências podem evitar a banalização do contato com o paciente, associado de forma frequente a visões biomédicas e reducionistas desta realidade. A tarefa de relatar tal encontro pareceu representar um convite ao desenvolvimento de habilidades empáticas, tais como introspecção, escuta, análise e interpretação das vivências subjetivas, já que a ausência de tais habilidades resulta em narrativas muito pobres de informações da história de vida e da doença.

\section{O ritual de iniciação do estudante: vivências e dificuldades}

O estudante de Medicina da segunda série vivencia um verdadeiro ritual de iniciação a cada momento nesta fase inicial do curso, quando começa a visitar o hospital com frequência semanal. Em busca de atender a suas necessidades, mudanças e pedidos de ajuda, lança mão de motivações conscientes e inconscientes. Sua imaturidade desperta sentimentos conflitantes frente à realidade acadêmica. Surgem dúvidas, incertezas, sentimentos ambíguos, desencantos e frustrações ${ }^{10}$.

Tendo adotado uma prática pedagógica problematizadora, a ESCS preconiza a inserção precoce do estudante nos serviços de saúde, exigindo-lhe, além da demonstração de um bom exame clínico, o enfrentamento de situações de cunho ético, emocional, psicológico e social. Observa-se a importância da constante reflexão sobre os seus valores e a prática médica humanística, num contexto de passagem e transformação.

Considerando que, durante os rituais e momentos de passagem, as identidades pessoais podem ser intercambiadas e enriquecidas pelo contexto cultural e educacional, acreditamos na não banalização de tais eventos e circunstâncias por meio da escrita livre e subjetiva, denominada medicina narrativa. O currículo médico tradicional enfoca demasiadamente a morte nos primeiros anos, e o cadáver acaba por protagonizar rituais de passagem, muitas vezes banalizados, que exaltam a verticalização dos saberes médicos diante do corpo dessacralizado, despido de história e de humanidade.

Nesses aspectos, também são importantes as experiências iniciais sobre "conhecer o outro". Muitas vezes, despertam-se no estudante sentimentos de culpa, já que, pelo contato com o paciente, obtêm-se dados da história do adoecer e de sua vida, e o estudante percebe estar aprendendo "sem dar nada em troca", sentindo-se "invasivo" e "especulador"11. 
"Durante toda a anamnese e o exame físico, me senti impotente diante do sofrimento de Marta, pois nem ao menos tenho conhecimento suficiente para ajudá-la a chegar a um diagnóstico e tratamento que melhorem sua qualidade de vida". (estudante do segundo ano)

Ao realizar o exame físico, tendo que "tocar", "palpar" e fazer exame ginecológico ou retal em seus pacientes, o estudante pode se deparar com seu despreparo técnico, que pode gerar sentimentos como vergonha e embaraço, ou ser despertado por emoções e angústias de intensidade variável, dependendo do nível de conflito que estiver vivendo ${ }^{11}$.

"Durante o exame físico, eu tive a oportunidade de realizar pela primeira vez as manobras de Leopold para a palpação do abdome gravídico. Isso me deixou muito nervosa, pois eu fiquei com medo de machucar a mãe e principalmente o bebê." (estudante do segundo ano)

Esta fase inicial é reveladora do perfil motivacional do estudante. $\mathrm{O}$ contato direto com o paciente, com novos cenários e a possibilidade de aprender com a experiência prática representam grandes fontes inspiradoras de processos de aprendizagem significativos e de uma reflexão baseada nas dificuldades vivenciadas. O estudante é estimulado a ser mais flexível e adaptativo diante das situações novas e provocativas.

"Eu já estava um pouco nervosa ao chegar, pois era apenas a segunda vez que íamos ao hospital no bloco de Ginecologia, e na primeira vez a paciente ficou muito agitada e se recusou a nos deixar concluir a anamnese e realizar o exame físico. Mas ao mesmo tempo eu também estava empolgada e animada pela perspectiva de realizar o exame de uma grávida ou puérpera." (estudante do segundo ano)

"Assim, aprendi que eu devo me adaptar ao paciente e que preciso estar preparada para lidar com as diversas reações que ele pode ter." (estudante do segundo ano)

No trecho acima, o estudante demonstra consciência da necessidade do treinamento para saber como lidar com as atitudes do paciente e com as próprias atitudes e percepções aliás, o que constitui a essência do processo de aprendizagem em PBL. Todo o estudo reflexivo de múltiplas teorias da comunicação e da psicologia médica permite o desenvolvimento de "novas lentes", ou seja, o estudante acaba por desenvolver uma visão e uma percepção mais aguçada da relação com o paciente a partir da reflexão sobre a prática.
Além disso, é fundamental que os alunos sejam capacitados a estabelecer um bom rapport no início da entrevista e a concluir e sintetizar todo o processo de entrevista no final, mantendo uma escuta ativa, um bom manejo entre perguntas abertas e fechadas, uma comunicação não verbal adequada e linguagem acessível ao paciente, inclusive saber lidar com as resistências e recusas deste.

"Foi bom descobrir logo de início, pois acredito que é a partir de pontos em comum entre examinador e assistido que se estabelece a empatia, tão fundamental para um bom rapport." (estudante do segundo ano) "[...] e eu já previa a dificuldade de abordagem do paciente em Ginecologia." (estudante do segundo ano)

O estudante é estimulado a verbalizar, escrever e elaborar vivências, às vezes associadas a conflitos mais profundos, tais como o medo de algumas doenças e o contato com a própria fragilidade emocional e/ou física, entre outros. Um exemplo é o susto diante de uma doença de pele, que é uma reação humana normal. $\mathrm{O}$ aspecto doentio de alguns pacientes pode causar repulsa ou apenas um susto, o que pode ser percebido pelo paciente, já que tudo é comunicado dentro da relação de forma verbal e não verbal.

Como nos diz Moacir Scliar ${ }^{12}$ :

A História da medicina é uma história de vozes. As Vozes misteriosas do corpo: O sopro, o sibilo, a crepitação. As vozes inarticuladas do paciente: O gemido, o grito, o estertor. As vozes articuladas do paciente: $A$ queixa, o relato da doença. A voz articulada do médico: A anamnese, o diagnóstico, o prognóstico... (p.7) "De qualquer forma, eu fui ao quarto designado e lá chegando reparei num montinho de coisas brancas que pareciam pele descascada. Ao olhar para o Sr. Fernando para me apresentar, notei que a pele descascada era dele e me assustei inicialmente por nunca ter visto nada igual." (estudante do segundo ano)

\section{Vivências emocionais no decorrer da formação médica}

A observação e a literatura indicam que os médicos têm dificuldades no trato dos aspectos emocionais em sua prática profissional. Com os avanços tecnológicos, a prática médica tornou-se mecanizada e distante dos pacientes. Os médicos atualmente apresentam a tendência de estabelecer relações distantes, sem confiabilidade, o que leva a um aumento da iatrogenia ${ }^{13}$. 
Algumas disciplinas nas escolas médicas tradicionais, como a Psicologia Médica e a Psiquiatria, vêm tentando enfatizar em suas práticas a importância dos fatores psicossociais, tanto no processo saúde-doença, como na atenção ao ser humano sadio ou doente ${ }^{13}$.

O grande desafio atualmente é fazer o médico, e até mesmo o estudante de Medicina, se interessar por aspectos emocionais em suas práticas. Na ESCS, as vivências emocionais são trabalhadas por meio de atividades nos cenários hospitalares, onde há contato dos estudantes com os pacientes e, por conseguinte, com seus conflitos e aflições. A supervisão destas atividades promove feedback e busca resgatar a subjetividade inerente ao modelo biopsicossocial adotado pela escola ${ }^{14}$.

O estudante vivencia as mais variadas situações emocionais e depois escreve e reflete sobre elas, por meio das narrativas médicas.

Se o estudante tiver uma atitude fria e impessoal, defensiva e sem abertura e sem uma escuta qualificada, seu relato acaba por denunciar este empobrecimento afetivo ou expressar diretamente suas dificuldades naturais. Por outro lado, o docente tem mais chance de flagrar esta banalização e este esvaziamento da dimensão humana inerente à prática médica por meio da leitura e análise reflexiva das narrativas.

"Eu senti pena. Senti pena da ignorância e da doença daquela mulher, do estado dela. Pensei: coitada, ela é só uma velha lascada, provavelmente com um baita de um câncer de ovário." (estudante do segundo ano)

Observa-se, nesse caso, a demonstração de uma atitude de frieza e repulsa diante da situação da paciente, sendo estes sentimentos geradores de resistência. Observa-se, inclusive, uma agressividade inconsciente velada e explícita, desencadeada pela realidade frágil da paciente e de sua doença e pela fragilidade do entrevistador. Ressalta-se que os estudantes utilizaram a narrativa como espaço catártico de elaboração de angústias, afetos negativos e conflitos intrapsíquicos suscitados pela proximidade do paciente, o que deve originar no docente avaliador uma postura de compreensão e de apoio, e não de julgamento.

Há uma grande diferença entre pena, piedade e compaixão. A compaixão pressupõe sensibilidade ética e implica a presença de respeito, caridade, amorosidade e diálogo simétrico. Já a pena está associada a um sentimento de superioridade, relação assimétrica e de exclusão do indivíduo sofredor. Ressaltamos a necessidade de um olhar que contemple o sofrimento em suas múltiplas perspectivas: filosófica, psicológica e antropológica ${ }^{15}$. Esta sensibilidade ética deve ser estimulada durante o curso:
"Confesso que por dentro estava muito emocionado, o recém-nascido aparentava estar bem, e fisicamente a mãe também, mas esta dava claros sinais de que rejeitava a criança, escondera de todos os seus familiares até aquele momento uma gravidez indesejada, fruto de uma relação forçada[...]" (estudante do segundo ano)

O estudante consegue descrever a tristeza e a frustração associadas à resistência da paciente em conversar. Essa angústia também pode ser geradora de resistência. A possibilidade de expressar tais afetos e de inclusive discuti-los em grupo é válida. Os alunos mais racionais e defensivos podem observar e visualizar a maturidade emocional daqueles mais expressivos. Alguns alunos gostam de compartilhar no pequeno grupo as suas narrativas, marcadas por uma subjetividade singularizada pela experiência. Todos passam a ter a oportunidade de se emocionar e acabam qualificando a relação interpares e a relação docente-discente.

O conceito de empatia envolve a capacidade cognitiva de compreender como a circunstância em que outra pessoa está vivendo influencia a vida desta, a reação emocional aos seus sentimentos e o poder de expressar compreensão e apoio para com o outro. Frequentemente, esses pontos são elencados nos projetos pedagógicos sob um referencial teórico clássico - a taxonomia de objetivos educacionais -, e divididos em três domínios: cognitivo, afetivo e psicomotor ${ }^{16}$.

É importante ressaltar que a empatia e a habilidade comunicacional aumentam a satisfação do paciente e a confiança, e intensificam a técnica de diagnóstico e tratamento do médico ${ }^{5-6}$.

Estudos propõem que os indivíduos empáticos tornam as relações mais agradáveis, reduzindo o conflito e o rompimento ${ }^{17}$. A habilidade de "ler" e valorizar os pensamentos e sentimentos das outras pessoas é o que, provavelmente, torna esses indivíduos mais bem-sucedidos em suas relações pessoais e profissionais ${ }^{18}$. Por outro lado, indivíduos não empáticos parecem carecer de inteligência social e podem se tornar prejudicados no trabalho, na escola, na vida conjugal, nas amizades e nas relações familiares, além de correrem o risco de viver à margem da sociedade ${ }^{19}$. Tais evidências justificam o nosso empenho curricular de valorizar a expressão escrita das vivências emocionais dos estudantes, o que pode promover maior inteligência emocional nos alunos.

\section{Benefícios pedagógicos da medicina narrativa: os desafios do desenvolvimento da empatia}

Os pacientes, com seus relatos pessoais, além do tratamento de suas queixas, querem que o médico compreenda de fato sua história em outros níveis além do biológico. Não basta 
realizar a inspeção, a palpação, a percussão e a ausculta. Na medicina, são muitas vozes e sons que acabam por permear este cenário e é preciso desenvolver o terceiro ouvido.

Uma educação médica que busque ativamente a face humana da medicina e que não seja deformadora e focada exclusivamente no modelo biomédico pode ser permeada por reflexões deste gênero:

"Eu consegui realmente entender o sofrimento dela de ter que ficar longe do marido e do filho e a situação por que ela estava passando de se sentir dividida nos seus desejos. Eu procurei expressar a minha empatia com relação ao que ela estava passando e seus sentimentos, e ela pareceu ficar satisfeita por não se ver julgada, apesar de continuar afirmando que queria o melhor para o filho." (estudante do segundo ano)

Os trechos acima exemplificam a dimensão emocional da empatia, em que o estudante se mobiliza diante da situação da paciente $^{16}$, o que evidencia o valor pedagógico da narrativa, visto que representa um espaço valioso de expressão livre de sentimentos e elaboração de conflitos intrapsíquicos. O manejo da contratransferência implica autoconhecimento e capacidade de introspecção, o que demanda apoio e feedback do docente. Observa-se que, quando não conta com este apoio no contexto acadêmico, o estudante acaba por reprimir e se esquivar desta dimensão afetiva, e muitas vezes conotá-la de forma pejorativa. As emoções são consideradas estorvos e elementos distratores de uma prática médica tecnicista. Este ideário supostamente cientificista perpassa a formação médica de forma silenciosa ou explícita, denunciando a fragilidade da formação psicológica dos futuros médicos. Neste sentido, a devolutiva das narrativas realizadas pelos docentes deve contemplar todas estas dimensões, possibilitando a ampliação do diálogo entre docente e discente, e uma crescente qualificação desta relação, que deveria ser mais simétrica em termos humanistas e assimétrica em termos técnicos...

"Percebi vestígios de tristeza quando the perguntei seu peso e altura, e, mesmo tendo valores bastante positivos e saudáveis, a jovem mãe afirmou temer que 'estragasse seu corpo', ainda com traços adolescentes." (estudante do segundo ano)

A história dessa jovem me impressionou muito, principalmente quando o Dr. X confirmou o grande risco que ela estava correndo. A todo momento da entrevista, ficava pensando como a sua coragem era admirável. O amor que ela dedicava a seu bebê, sem nem ter nas- cido ainda, já era o de mãe, incondicional. (estudante do segundo ano)

A escuta ativa pressupõe a arte e a técnica da escuta e da manifestação de apoio e interesse. O ideal é que os estudantes possam aos poucos se sentir mais confortáveis diante das demandas afetivas dos pacientes, o que promove um manejo mais eficiente e reflexivo do próprio comportamento e de suas expressões não verbais na relação interpessoal. Ressaltamos a complexidade crescente de significados e demandas que permeiam a relação estudante-paciente.

"Entendi que, muitas vezes, quando não sabemos o que dizer, o silêncio é a melhor resposta. Escutar o paciente, demonstrando empatia por ele, é fundamental em nossa profissão." (estudante do segundo ano)

"Entendo que é bom para o paciente que o médico se preocupe com o estado psicológico da paciente, mas ele pode ser ainda melhor se puder realmente fazer algo pelo paciente, ao invés de se limitar a uma reflexão introspectiva. Sei que isso pode levar um bom tempo, mas acredito que, no dia em que puder dar uma palavra de consolo e perceber que aquilo fez diferença e que foi bom para a paciente, aí sim me sentirei plenamente realizada com a profissão que escolhi." (estudante do segundo ano)

Já neste trecho, está evidente uma reflexão quanto à relação médico-paciente e aos benefícios que pode trazer ao paciente. $\mathrm{O}$ estudante visualiza a importância da humanização e da escuta como fonte de realização pessoal. Nesse sentido, a empatia passa a ser uma meta e um valor a ser atingido. Isto envolve um esforço de autoconhecimento e cognitivo na busca de identificação com o paciente, mesmo quando este vive uma realidade bastante diferente daquela do estudante ${ }^{16}$.

Publicações recentes revelam que a empatia dos estudantes de Medicina tende a decrescer ao longo do seu percurso nas escolas médicas, em particular com o primeiro ano de contato com a realidade clínica ${ }^{20}$. Na ESCS, foi observado que alguns estudantes expressam ter dificuldade de construção de uma relação empática nos primeiros contatos com os pacientes. A utilização de tal ferramenta representa uma estratégia de diminuir o risco de erosão da empatia na $\mathrm{ESCS}^{21}$, na medida em que o estudante pode receber um feedback do docente. Tal feedback deve ser dado de forma individualizada e dialógica, representando uma oportunidade de crescimento pessoal e profissional. Muitas narrativas são lidas nos pequenos grupos, caso seja o desejo do autor. 
"Até aquele momento me sentia distante da paciente, desconfortável. Esse desconforto passou a ficar físico. Sentia minhas pernas moles e sem firmeza, comecei a ficar inquieta, tentando apoiar minha perna em algum lugar e assim apoiar o caderno com as anotações colhidas." (estudante do segundo ano)

Em algumas situações, os estudantes utilizam a narrativa como um espaço catártico, uma vez que ela permite exteriorizar sentimentos negativos transferenciais evocados pela relação com o paciente, como culpa, vergonha, raiva e impotência, muitas vezes, geradores de conflitos intrapsíquicos conscientes e inconscientes. Mesmo nestes casos, percebemos a importância da confiança da estudante no docente e na instituição:

"Eu sentia vergonha. Vergonha de estar participando daquilo, daquele momento. Sob o juízo daquela senhora decrépita e rebelde, e das outras que a assistiam... como se eu fosse a culpada pelo que aconteceu e pelo que acontecia com ela, como se eu fosse a continuação daquela injustiça, daquela tragédia e acima de tudo a estivesse importunando. Eu, porém, não conseguia fazer nada, somente "passar mal", sofrendo da minha lipotimia ou da minha covardia. [...] Senti raiva daquela ignorância de que outrora eu sentira pena." (estudante do segundo ano)

Os estudantes reconhecem que a empatia implica habilidades de escuta ativa, mas, sobretudo, a encaram como uma meta a alcançar. A dimensão valorativa atribuída à empatia, por meio da medicina narrativa, funciona como um antídoto ao risco de banalização das vivências e da relação com o paciente.

\footnotetext{
"Senti que ela desejava desabafar e fiz alguns segundos de silêncio. Então, Joana encheu os olhos de lágrimas e disse não estar aguentando o ambiente da enfermaria." (estudante do segundo ano)

"Aquilo era muito, muito triste. Imaginei como seria a cabeça daquela mulher, com seus 35 anos e tantas perdas. E o marido, os pais, os irmãos, como será que eles enfrentavam isso? Será que lhe davam apoio? Ou será que desaconselhavam que ela ficasse grávida novamente?" (estudante do segundo ano).
}

A literatura indica que o nível de empatia é mais sensível à mudança do que as habilidades comunicacionais. Observou-se que os grupos de estudantes com alta empatia desde o início do curso de Medicina tendiam à queda, e que os com baixa empatia (75\% do grupo), ao crescimento. A maioria dos estudantes parece se beneficiar com estratégias pedagógicas inovadoras, o que justifica esforços, principalmente no que concerne à expressão da empatia, que é o grande desafio ${ }^{22,23}$.

A relação estudante-paciente pode implicar o risco de um superenvolvimento emocional. O currículo médico deve promover o amadurecimento emocional, bem como um suporte psicológico ao estudante, considerando e restringindo o risco de um excessivo contágio emocional ou, por outro lado, de um esfriamento e distanciamento defensivo associado a uma prática médica desumanizada.

"[...] ainda não aprendi a dosar o meu envolvimento com os casos clínicos. Não consegui esquecer o caso do João, o que me fez sofrer." (estudante do segundo ano) "Fitei então o seu semblante: aquele ar amargo, ranzinza, sombrio causava repulsa." (estudante do segundo ano)

O método de construção de narrativas pode aguçar o juízo a respeito dos aspectos relacionados à forma como são construídas as narrativas de um caso ou de um dilema ético, das vozes às quais é dada autoridade, dos planos considerados relevantes e, por último, das possíveis soluções consideradas ${ }^{15}$. A virtude da abordagem narrativa é o fato de sua utilização forçar os profissionais de saúde a expor suas concepções e preconceitos, confrontá-los e, em última instância, trazer lealdade para o diálogo com o outro.

O médico se torna, então, ao mesmo tempo, leitor e narrador, decodificador de palavras e de corpos repletos de signos, cabendo a ele fazer uso de sua subjetividade para cumprir essa multitarefa. A subjetividade é trazida ao campo da educação como uma matéria-prima em torno da qual giram as engrenagens desse campo com suas práticas e finalidades ${ }^{24}$. A plenitude do exercício clínico passa, então, a se valer do instrumental técnico-científico objetivo, atrelado às interpretações e intuições dos médicos ${ }^{25}$.

A subjetividade dá abertura a estudos de fenômenos complexos, numa proposta de conhecimento construtivo-interpretativo, que se enquadra na epistemologia qualitativa ${ }^{26}$. Múltiplas técnicas de análise das comunicações foram operacionalizadas pelas ciências humanas, sendo que os dados, como os presentes em medicinas narrativas, representam um universo de sentidos e vivências enveredados no enfoque da metodologia qualitativa. Tal epistemologia proporciona ao pesquisador liberdade para a realização da atividade interpretativa, que é interligada a evidências empíricas ${ }^{27}$. 
Aumento da complexidade da tarefa no terceiro ano por meio de taxonomias mais altas

No final do terceiro ano, é solicitado ao estudante o desenvolvimento de uma narrativa na primeira pessoa. $\mathrm{O}$ relato soa como se fosse o próprio paciente revelando seus sentimentos e dores. As narrativas realizadas na primeira pessoa convidam o estudante a, realmente, se colocar no lugar do paciente e representam um desafio pedagógico bastante fértil, como podemos observar:

"Contei a elas o quanto tive uma vida sofrida. Contei que desde a infância vivi reprimida por meus pais, que não tive infância, que não tive adolescência. Não neguei minhas frustrações no amor. Tornei-me dependente química do cigarro, motivo pelo qual estou aqui, deitada nesta cama. Sem um diagnóstico, sem saber o que tenho, sem saber se vou sair daqui." (estudante do terceiro ano

"Admirei como que em tão pouco tempo falei tantas coisas sobre mim. Nem as conhecia, nem o nome delas eu sei. Não sei nada sobre elas." (estudante do terceiro ano)

O esforço cognitivo e afetivo de se reconhecer como o outro e de superar uma alteridade radicalmente diferente da sua cria um elo na relação. Esta busca de identificação com o paciente implica a superação de barreiras. No currículo da ESCS, este desafio ocorre desde as primeiras séries.

"Era tão estranho o contraste! A vida, beleza, simpatia daquela com a decadência da senhora nossa paciente." (estudante do segundo ano)

\section{CONSIDERAÇÕES FINAIS}

As evidências atuais constituem um indicador claro para as escolas médicas de que elas devem buscar novas estratégias de promoção do comportamento empático nos futuros médicos. A expansão da investigação acerca da evolução da empatia é fundamental para identificar melhores estratégias a serem aplicadas. Para esse efeito, deve-se dispor de instrumentos adequados para aferir empatia em múltiplos contextos formativos e culturais.

Vários instrumentos têm sido desenvolvidos para medir a empatia ${ }^{28}$, em sua maioria medidas de autorrelato. Alguns deles são aplicáveis ao contexto médico, mas na literatura nacional não foram identificados trabalhos inspirados em tais instrumentos, o que indica pouca visibilidade desta temática na literatura especializada em educação médica. Tem-se estudado a validade destes instrumentos, relacionando-se a pontuação nas escalas de autorrelato e o comportamento empático relatado pelo paciente ${ }^{29}$.

A medicina narrativa mostrou-se uma estratégia pedagógica válida na ESCS, na medida em que possibilitou a expressão, a elaboração e a reflexão de conteúdos humanísticos inerentes à prática médica.

Observou-se que a medicina narrativa representou uma abordagem mediadora fundamental para promover o autoconhecimento e a humanização da relação com o paciente e com o próprio docente. A possibilidade de os estudantes, no início da graduação, expressarem os próprios medos e angústias representa uma mudança de lógica acadêmica - onde há espaço para compreensão e apoio de todos os atores envolvidos no processo de aprendizagem -, bem como constitui uma etapa e um requisito necessário ao aprendizado de diferentes dimensões inerentes ao comportamento empático.

Observou-se maior desenvolvimento de habilidades empáticas no terceiro ano, quando os estudantes já haviam tido mais oportunidades de aprendizagens significativas, de reflexões inspiradas na prática e de superação das próprias limitações. No segundo ano, o teor das narrativas confirma a necessidade de exteriorização dos próprios conflitos e de barreiras emocionais, já que esta série representa uma fase de adaptação e familiarização ao contexto hospitalar. É fundamental que o estudante passe por todas estas etapas de aprendizagem das habilidades empáticas e afetivas.

A adesão crescente dos estudantes e a riqueza e diversidade dos relatos indicaram a validade da medicina narrativa como incitadora de maior sensibilidade ética e afetiva diante dos dramas e dilemas vivenciados pelos pacientes. A maior contribuição desta abordagem é a não banalização das emoções e vivências subjetivas inerentes ao aprendizado médico. Por ser um estudo preliminar, restrito a alunos do segundo e terceiro ano, não podemos afirmar a consolidação de tais competências empáticas. Por outro lado, pudemos observar a diversidade e riqueza de dimensões humanistas vividas e percebidas pelo estudante de Medicina a partir do encontro com o paciente.

Neste sentido, a medicina narrativa constituiu um instrumento válido de avaliação do desenvolvimento de competências humanísticas no currículo médico da ESCS, pois permitiu ao docente observar e analisar o desenvolvimento ou a falta de desenvolvimento de múltiplas habilidades dos discentes ao longo do curso, associadas à qualidade da textualidade, coesão, densidade teórica e humanística, criatividade e sensibilidade do texto produzido. 
Observa-se que a adesão voluntária e espontânea ao instrumento é crescente. Muitos docentes e discentes acreditam na efetividade da medicina narrativa, embora o maior desafio seja ainda a falta de capacitação de alguns docentes, o que pode comprometer a qualidade do diálogo e das devolutivas realizadas durante o processo das narrativas. Este estudo preliminar e de cunho qualitativo indica a necessidade de realizar novos estudos com metodologias mistas, visto que as escalas de empatia ainda necessitam ser validadas em nosso país e contextualizadas para a nossa realidade. A constatação de uma evolução nas competências afetivas e empáticas dos estudantes permite-nos afirmar a presença de uma integração longitudinal do currículo da ESCS em termos de desenvolvimento de habilidades clínicas do estudante, mesmo que ainda não integradas às técnicas semiológicas.

\section{REFERÊNCIAS}

\section{Almeida HO, Alves NM, Costa MP, Trindade EMV, Muza} GM. Desenvolvimento de Competências em Comunicação: Uma Experiência com a Medicina Narrativa. Rev Bras Educ Med. 2005;29(3):208-16.

2. Conselho Nacional de Educação. Câmara de Educação Superior. Resolução no 4 institui diretrizes curriculares nacionais do curso de graduação em Medicina. Diário Oficial da União, Brasília, 7 nov 2001.

3. Gaydos HL. Understanding personal narratives: an approach to practice. J Adv Nurs. 2005; 49(3):254-9.

4. Charon R. Narrative and Medicine. N Engl J Med. 2004;350(9):862-4.

5. Charon R. Literary Concepts for Medical Readers: Frame, Time, Plot, Desire. In: Hawkins AH, McEntyre MC, eds. Teaching literature and medicine. New York: Modern Language Association of America; 2000; p.29-42.

6. Charon R. Narrative and Medicine. A Model for Empathy, Reflection, Profession, and Trust. JAMA. 2001 [acesso em 4 jun. 2005];286(15):1897-902. Disponível em: http://cce. stanford.edu/curriculum/courses/ethmedreadings04/ em2penal.pdf.

7. Fundação de Ensino e Pesquisa em Ciências da Saúde. Projeto Pedagógico. Brasília, DF: [s.n.]; 2001. p. 29 e 41.

8. González Rey F. Epistemologia Cualitativa y Subjetividad. La Habana: Editorial Pueblo y Educación; 1997.

9. Charon R. Narrative Medicine: form, function, and ethics. Annals of Internal Medicine. 2001; 134(1):83-7.

10. Trindade LMDF, Vieira MJ. Curso de Medicina: motivações e expectativas de estudantes iniciantes. Rev Bras Educ Med. 2009;33(4):542-54.
11. Avancine MATO, Jorge MR. Medos, atitudes e convicções de estudantes de medicina perante as doenças. Psiq Prat Med. 2000;33(1):2-9

12. Scliar M. A paixão transformada. [S.I.]: Cia das Letras; 1996.

13. Cassorla RMS. Dificuldades no lidar com aspectos emocionais na prática médica: estudo com médicos no início de grupos Balint. Rev. ABP-APAL. 1994;16 (1):18-24.

14. Trindade EMV. Resgatando a dimensão subjetiva e biopsicossocial da prática médica com estudantes de medicina: relato de caso. Rev Bras Educ Med. 2005;29(1):48-50.

15. Trindade EMV. Uma perspectiva histórica do sofrimento humano: considerações éticas no âmbito da saúde. Rev. Saúde Dist. Fed. 2004;15(1/2):9-18.

16. Tapajós R. Objetivos educacionais na pedagogia das humanidades médicas: taxonomias alternativas (campos de significado e competências). Rev Bras Educ Med. 2008;32(4):500-6. DOI: dx.doi.org/10.1590/S010055022008000400013

17. Davis MH. Measuring individual differences in empathy: evidence for a multidimensional approach. J Personality Social Psychol. 1983;44:113-26.

18. Ickes W. Introduction. In: W Ickes, org. Empathic accuracy. New York: Guilford; 1997; p. 1-16.

19. Goleman D. Inteligência emocional. Rio de Janeiro: Objetiva; 1995

20. Hojat M, Vergare MJ, MaxwellK, Brainard G, Herrine SK, Isenberg GA, et al. The devil is in the third year: a longitudinal study of erosion of empathy in medical school. Acad Med. 2009;84(9):1182-91. DOI: 10.1097/ ACM.0b013e3181b17e55.

21. Balduino PM, Palis, FP, Paranaíba VF, Almeida HO, Trindade EMV. Perspectiva do Paciente no Roteiro de Anamnese: o Olhar do Estudante. Rev Bras Educ Med. 2012;36(3):335342. DOI: dx.doi.org/10.1590/S0100-55022012000500007

22. Dereboy C, Harlak H, Gürel S, Gemalmaz A, Eskin M. Teaching empathy in medical education. Turk Psikiyatri Derg. 2005;16(2): 83-9.

23. Winefield HR, Chur-Hansen A. Evaluating the outcome of communication skill teaching for entry-level medical students: does knowledge of empathy increase? Med Educ. 2000;34: 90-4.

24. Birman J. Subjetividade, contemporaneidade e educação. In: Candau VM, org. Cultura, linguagem e subjetividade no ensinar e aprender. Rio de Janeiro: DP\&A; 2000; p. 11-28

25. Grossman E, Cardoso MHCA. As narrativas em medicina: contribuições à prática clínica e ao ensino médico. Rev Bras Educ Med. 2066;30(1):6-14. DOI: dx.doi.org/10.1590/ S0100-55022006000100002 
26. González Rey FL. Pesquisa qualitativa em psicologia: caminhos e desafios. São Paulo: Pioneira Thomson Learning; 2002.

27. Trindade EMV. A crise da ciência Moderna na Psicologia: reflexões sobre outras Saídas históricas, tais como a 'Epistemologia Qualitativa'. Comun Ciênc Saúde. 2009;20(2):16774

28. May BA, Alligood MR. Basic empathy in older adults: conceptualization, measurement, and application. Issues Ment Health Nurs. 2000;21(4):375-86.

29. Hojat M, Gonnella J, Nasca T, Mangione S, Vergare M, Magee M. Physician Empathy: Definition, Components, Measurement, and Relationship to Gender and Specialty. Am J Psychiatry. 2002;159:1563-9.

\section{CONTRIBUIÇÃO DOS AUTORES}

Natália Souza Medeiros e Thais Rabelo dos Santos: revisão bibliográfica em bases de dados cientificamente válidas, selecionando artigos relevantes para solidificar o embasamento do trabalho; coleta de narrativas médicas, mediante concordância dos sujeitos da pesquisa e elucidação sobre a pesquisa; revisão das narrativas para categorização das grandes zonas de sentido elucidativas do saber investigado; reflexão sobre tais categorias; discussão dos resultados encontrados, correlacionando-os à bibliografia pesquisada; confecção do artigo final; revisão do trabalho final, para assegurar o emprego das normas técnicas. Eliana Mendonça Vilar Trindade: revisão bibliográfica; apresentação do estudo aos estudantes previamente à análise das narrativas médicas, visando à elucidação dos mesmos em relação ao estudo; discussão dos resultados, correlacionando-os à bibliografia pesquisada; confecção e revisão do artigo final. Karlo Jozefo Quadros de Almeida: revisão do artigo final; confecção do resumo.

\section{CONFLITO DE INTERESSES}

Declarou não haver.

\section{ENDEREÇO PARA CORRESPONDÊNCIA}

Natália Souza Medeiros

Escola Superior de Ciências da Saúde (ESCS)

SMHN - Quadra 501 - Bloco A - Brasília

CEP 70710-904 - DF

E-mail: natalia.medeiros@gmail.com 